\title{
PARENTING SELF EFFICACY AYAH PADA NUCLEAR DAN EXTENDED FAMILY
}

\author{
Sri Hardyanti ${ }^{1}$, Diah Karmiyati ${ }^{2}$, Diana Savitri Hidayati ${ }^{3}$ \\ Fakultas Psikologi, Universitas Muhammadiyah Malang \\ srihrdynti@gmail.com
}

\begin{abstract}
Bentuk keluarga di Indonesia cukup beragam, namun secara garis besar bentuk keluarga tersebut dibagi menjadi nuclear family dan extended family. Kedua bentuk keluarga ini memiliki perbedaan mendasar dari anggota keluarga yang ada dalam keluarga tersebut, dimana keduanya mampu menimbulkan dinamika yang berbeda khususnya dari ketersediaan dukungan sosial dan berdampak terhadap Parenting SelfEfficacy (PSE) ayah. Penelitian ini bertunjuan untuk mengetahui apakah ada perbedaan $P S E$ ayah pada nuclear dan extended family yang diukur dengan menggunakan Fathering Self-Efficacy Scale (FSES), dimana desain penelitian yang digunakan adalah penelitian kuantitatif. Teknik sampling dalam penelitian ini adalah snowball dengan jumlah subjek sebesar 200 orang dan data yang didapatkan dari subjek dianalisis dengan menggunakan uji Mann Whitney. Hasil penelitian menunjukkan nilai $\mathrm{Z}=$ -1.273 dan $\mathrm{p}=0.216$ ( $>0.05$ ) sehingga dapat diketahui bahwa tidak terdapat perbedaan yang signifikan terhadap PSE ayah pada nuclear dan extended family.
\end{abstract}

Kata Kunci: Parenting Self-Efficacy, nuclear family, extended family

There are a lot of family form in Indonesia, but the outline of that form devides into nuclear family and extended family. The basic difference of both of them is family member who existing in and causes a different dynamic spesifically the availibilty of social support, so at the end of the day it will affect on father's Parenting Self-Efficacy (PSE). The aim of this study is identying the differences of PSE level between father in nuclear family and extended family by using a Fathering Self-Efficacy Scale (FSES) with quantitative as a research design. Snowball is a sampling technique with 200 subjects and the data is analyzed by using Mann Whitney test. The result shows $Z$ score $=-1.273$ and $p=0.216$ $(p>0.05)$, therefore there is no significant differences of PSE level between father in nuclear and extended family.

Keywords: PSE, nuclear family, extended family 
Parenting merupakan salah satu isu utama yang dibahas dalam kehidupan keluarga, yakni mengacu pada aspek membesarkan anak disamping ikatan biologis yang terjadi, dimana istilah ini merupakan suatu proses mengembangkan dan mendukung perkembangan fisik, emosi, sosial, dan intelektual anak sejak bayi hingga ia dewasa (Adimora, et al., 2015). Kazdin (2014) menjelaskan bahwa pelaksanaan parenting memiliki 3 tujuan utama yaitu menjamin kesehatan dan keselamatan anak, mempersiapkan kehidupan anak agar menjadi individu yang produktif, dan mewarisi nilai-nilai budaya. Hal yang penting dalam pelaksanaan parenting ini adalah kualitas hubungan antara orang tua dan anak untuk perkembangan anggota keluarga, khususnya anak itu sendiri.

Berbicara mengenai kualitas hubungan antara orang tua dan anak, maka hal yang harus diperhatikan adalah seberapa efektif peran kedua orang tua sehingga menghasilkan hubungan yang berkualitas. Fenomena yang kerap ditemukan di lingkungan adalah peran dan keterlibatan ayah lebih difokuskan pada kemampuannya untuk memenuhi kebutuhan finansial anak, sedangkan keterlibatan dalam pengasuhan sehari-hari seperti menyuapi bayi maupun membantu anak untuk mengerjakan tugas dari sekolah lebih diidentikkan dengan peran dan keterlibatan ibu dalam parenting. Selain itu, seiring perkembangan teknologi waktu yang dihabiskan ayah bersama anaknya semakin didefinisikan sebagai keberadaan secara fisik saja sebab penggunaan telepon genggam lebih menyita perhatian ayah dibandingkan melakukan interaksi bersama anak. Berkaitan dengan ini, Dagun (2013) menyatakan bahwa jumlah waktu yang dihabiskan antara orang tua bersama anak bukanlah faktor penentu yang dapat menimbulkan pengaruh efektif, akan tetapi yang menjadi fokus perhatian adalah apa dan bagaimana yang dilakukan oleh orang tua saat menghabiskan waktu bersama anaknya. Secara spesifik, terdapat 3 peran utama yang dimiliki oleh ayah diantaranya adalah berperan dalam aspek afeksi, pengasuhan, dan dukungan finansial. Aspek afeksi yaitu ayah berperan untuk memberikan perhatian, membahagiakan, memberikan rasa aman, serta memberikan perhatian saat sakit. Aspek selanjutnya adalah aspek pengasuhan, ayah berperan untuk meluangkan waktu, memberi nasehat, mengingatkan, mengajarkan serta menjaga. Aspek ketiga yakni aspek dukungan finansial, ayah berperan memberikan makan, memberi uang jajan, serta memenuhi kebutuhan hidup (Harmaini, et al., 2015).

Ayah memiliki peranan penting dalam kehidupan anak sebab dibutuhkannya keterlibatan dalam berbagai aspek fisiologis maupun psikologis. Ketika peranan dan keterlibatan tersebut mampu untuk dijalankan secara efektif, maka akan berdampak positif terhadap pertumbuhan dan perkembangan anak. Hasil penelitian Volker \& Gibson (2014) telah membuktikan bahwa peningkatan level kuantitas dan kualitas dari keterlibatan ayah akan berdampak positif terhadap kehidupan sosial, emosi, dan kognitif anak. Hal ini tentunya akan selaras dengan kecilnya kemungkinan untuk anak terlibat dalam kenakalan atau berbagai perilaku berisiko. Penelitian lain menjelaskan bahwa interaksi yang dijalin oleh ayah mampu mencegah terjadinya hambatan kognitif pada bayi, dimana interaksi tersebut dilakukan dalam bentuk aktivitas yang bersifat menstimulus kognitif, kehangatan emosi, dan perawatan fisik (Fogarty \& Evans, 2009). Melihat pentingnya peran dan keterlibatan ayah dalam kehidupan anak, maka hal utama

yang harus diidentifikasi adalah faktor yang mendorong keterlibatan ayah tersebut. Trahan (2017) mengungkapkan bahwa terdapat hubungan yang signifikan antara 
keterlibatan ayah dan self-efficacy yang dimilikinya. Apabila ayah memiliki keyakinan diri yang tinggi akan kemampuannya untuk mengasuh anak, maka akan tiga kali lebih mungkin untuk dirinya terlibat dalam pengasuhan anak, sedangkan ayah yang terlibat akan memungkinkan untuk dua kali lebih percaya diri. Bandura (dalam Gao et al., 2014) menjelaskan bahwa self-efficacy adalah keyakinan seseorang mengenai kompetensi yang dimiliki dalam menyelesaikan suatu situasi/tugas tertentu. Secara umum, konsep selfefficacy hampir dibahas dalam seluruh lini kehidupan manusia, termasuk dalam ranah parenting yang disebut sebagai parenting self-efficacy (PSE).

PSE adalah komponen kognitif dalam kompetensi pengasuhan (parenting) yang menunjukkan persepsi orang tua mengenai kompetensi yang dimilikinya dalam menjalankan perannya sebagai orang tua dan kemampuan untuk mempengaruhi perilaku dan perkembangan anak secara positif (Coleman \& Karraker, 2002). Melalui PSE ini, ayah akan yakin terhadap kemampuan dan kompetensinya sebagai orang tua sehingga ia dapat menjalankan perannya secara efektif yang pada akhirnya anak akan mengalami perkembangan bersifat positif, seperti anak akan lebih percaya diri, memiliki kontrol diri yang lebih baik sebab mampu menghindarkan diri untuk terlibat dalam kenakalan remaja, dan lain sebagainya. Selain itu pentingnya PSE ditunjukkan dalam penelitian Garcia \& Alampay (2012) bahwa ketika ayah sedang menghadapi peristiwa dalam kehidupan yang menimbulkan stress, namun memiliki PSE yang tinggi maka akan semakin kecil kemungkinan untuk ayah melakukan permusuhan dan agresi terhadap anak.

Berdasarkan uraian sebelumnya telah diutarakan bahwa PSE pada ayah adalah suatu hal yang urgen sehingga dapat dikatakan sebagai faktor vital terhadap keterlibatan ayah dan dampak positif yang ditimbulkan dalam perkembangan anak, akan tetapi terdapat suatu tantangan yang harus dihadapi dalam membahas konsep ini. Secara umum, PSE kerap diidentikkan dengan keyakinan yang dimiliki oleh ibu (maternal) dalam proses parenting, bahkan berbagai penelitian menunjukkan hasil yang konsisten bahwa PSE ibu lebih tinggi dibandingkan PSE ayah. Hasil yang cenderung konsisten tersebut disebabkan karena instrumen yang digunakan untuk mengukur PSE dilandasi oleh konsep-konsep pengasuhan yang mengarah pada peran khas ibu dalam parenting, padahal yang harus diingat adalah ayah juga memiliki peran yang bersifat khas dalam pelaksanaan parenting tersebut (Sevigny, et al., 2016). Selain itu, minimnya fokus perhatian pada PSE ayah didukung oleh Graeme \& Russell (dalam Dagun, 2013) yang membuktikan meskipun kaum ayah cenderung kurang terlibat dalam memberi makan kepada bayinya namun sebenarnya mereka memiliki kepekaan dan respon yang sama dengan yang dimiliki oleh ibu.

Terlepas dari tantangan yang dihadapi dalam membahas konsep PSE ayah, tindakan yang sebaiknya dilakukan adalah menyelidiki hal-hal yang berkontribusi terhadap PSE ayah agar kedepannya dapat ditentukan langkah yang harus diambil untuk menangani PSE tersebut sehingga berada pada level yang tinggi. Sevigny \& Loutzenhiser (2009) membuktikan prediktor PSE pada ayah adalah parenting stress dan keberfungsian hubungan, seperti kepuasan pernikahan, keberfungsian keluarga, dan lain sebagainya. Selaras dengan hal ini, Freistadt \& Strohschein (2012) mengungkap bahwa bentuk keluarga yang berbeda akan menimbulkan perbedaan keberfungsian keluarga. Disamping itu, Coleman \& Karraker (1997; 2000) juga mengemukakakn bahwa faktor yang mempengaruhi PSE beberapa diantaranya adalah verbal persuasion dan dukungan sosial serta pernikahan. Verbal persuasion adalah umpan balik verbal dari orang lain terhadap pencapaian yang dimiliki oleh ayah dalam pelaksanaan pengasuhan, sedangkan 
dukungan sosial adalah dukungan yang diperoleh ayah dari lingkungan sekitarnya. Faktor-faktor yang mempengaruhi PSE ayah tersebut menunjukkan bahwa keberadaan orang-orang di sekitar ayah mampu mempengaruhi PSE yang dimilikinya. Apabila berbicara mengenai keberadaan orang sekitar yang dalam hal ini anggota keluarga, maka perbedaan bentuk keluarga menunjukkan jumlah dan anggota keluarga yang berbeda pula. Bentuk keluarga yang masih khas di Indonesia, khususnya daerah yang bukan perkotaan adalah extended family, meskipun pada faktanya bentuk ini semakin mengerucut menjadi keluarga yang berbentuk nuclear family. Edlund \& Rahman (2005) menyatakan bahwa extended family diidentikkan dengan mayoritas keluarga di Asia, sedangkan nuclear family sangat lekat dengan bentuk mayoritas keluarga di benua Eropa.

Nuclear family merupakan bentuk keluarga yang hanya beranggotakan ayah, ibu, dan anak. Kelebihan utama dari nuclear family ini adalah suami dan istri akan lebih memiliki privasi sehingga mereka merasa bahwa adanya kebebasan untuk menentukan arah kehidupan sebagaimana yang mereka harapkan (Yorburg, 2002). Akan tetapi, disisi lain kelemahan dari nuclear family adalah besarnya kemungkinan untuk menitipkan anak pada baby-sitter sehingga anak akan bertumbuh dalam keadaan kurang mengenal nilainilai yang dianut keluarga, dimana hal ini juga berimplikasi terhadap minimnya perasaan aman dan minimnya dukungan sosial bagi orang tua (Bansal, et al., 2014). Selain itu, suatu penelitian membuktikan bahwa bentuk keluarga akan memberikan perbedaan pemaknaan peran dan keterlibatan pada ayah yang berusia remaja. Ketika mereka terbentuk sebagai nuclear family, maka kemandirian dan partisipasi aktif dalam parenting akan lebih dituntut sebab tidak adanya figur pengganti lain yang dapat membantu mengasuh anak. Ayah yang berusia remaja akan mengalami perasaan bebas berekspresi sebagai individu maupun sebagai kepala keluarga, dalam hal ini mereka mampu untuk menemukan totalitas dalam mengorganisir keluarganya secara mandiri yang sesuai dengan prinsip dan kebutuhan mereka tanpa merasa sungkan sebab tidak adanya anggota keluarga lain (Malelak \& Afiatin, 2015).

Apabila dikaitkan dengan faktor PSE yang dijabarkan oleh Coleman \& Karraker (1997), maka PSE ayah remaja dalam nuclear family dapat terbentuk karena adanya proses direct experience yakni ayah remaja mampu belajar secara langsung dari kegagalan serta keberhasilan saat melakukan tugas parenting. Selain itu, hal ini juga didukung dengan salah satu ciri tingkat PSE yang tinggi yaitu secara kuat berhubungan dengan kapasitas orang tua dalam memberikan stimulasi, adaptif dan membesarkan anak, serta keterlibatan dalam interaksi pengasuhan secara langsung (Coleman \& Karraker, 2002; Mash \& Johnston, 1985). Disamping sisi positif, nuclear family ternyata juga memiliki kelemahan sebagaimana yang dijelaskana oleh Malelak \& Afiatin (2015) bahwa ayah yang berusia remaja akan cenderung masih kesulitan dalam perekonomian dan keterbatasan sumber daya yang dapat menimbulkan ketergantungan pada orang tuanya sehingga menimbulkan rasa malu dalam diri ayah remaja sebab merasa tidak efektif menjalankan perannya. Sesuai dengan pejelasan dari Garcia \& Alampay (2012) bahwa kondisi finansial untuk membesarkan anak dapat menjadi situasi yang membuat stress pada ayah sehingga mempengaruhi PSE yang dimilikinya.

Bentuk lain dari keluarga adalah extended family, yakni keluarga yang terdiri atas ayah, ibu, anak, nenek, kakek, dan/ atau anggota keluarga besar lainnya, bertempat tinggal di rumah yang sama, serta setiap hari saling berinteraksi (bertatap muka) (Yorburg, 2002). Seperti halnya nuclear family, bentuk keluarga extended juga memiliki sisi positif dan sisi negatif terhadap efektivitas peran dan PSE ayah dalam keluarga tersebut. Bansal, et 
al. (2014) mengutarakan bahwa sisi positif dari extended family adalah anggota keluarga tidak akan merasa sendirian, akan ada anggota keluarga lain yang membantu menjaga anak, pekerjaan rumah dapat dibagi, beban yang dirasakan tidak ditanggung secara individual namun cenderung dibagi kepada anggota keluarga lainnya, serta adanya pengarahan dan perhatian.

Selain itu, penelitian lainnya juga membuktikan bahwa dalam extended family terjadi proses transfer pengetahuan dan nilai-nilai kekeluargaan yang meliputi dukungan, perhatian, perasaan senasib-sepenanggungan, serta adanya bantuan dalam pengasuhan anak. Apabila dikaitkan dengan faktor PSE yang dikemukakan oleh Coleman \& Karraker (1997), maka sisi positif dari extended family dapat diidentikkan dengan faktor PSE khususnya faktor vicarious learning, yaitu ayah dapat melakukan proses modeling dalam hal parenting sehingga mampu mendorong PSE yang dimilikinya.

Hsieh, et al. (2008) menjelaskan bahwa di Taiwan, extended family merupakan bentuk keluarga yang lazim di temui di masyarakat. Bentuk keluarga ini menunjukkan dukungan sosial yang lebih baik dan anak-anak dapat memperoleh perhatian yang lebih banyak, khususnya dari kakek dan nenek. Akan tetapi, orang tua pada nuclear family dengan anak yang mengalami keterlambatan perkembangan memiliki kepuasan kesehatan yang lebih baik dibandingkan dengan orang tua di extended family. Hal ini disebabkan karena dalam extended family, akan timbul konflik seputar perawatan anak serta meningkatnya stress orang tua yang disebabkan karena partisipasi dan keterlibatan pengasuhan yang berlebihan dari berbagai anggota keluarga. Sebaliknya, pada nuclear family orang tua akan mampu untuk menentukan sendiri perawatan yang dianggap tepat untuk anak mereka (Hsieh, et al., 2008). Uraian di atas menjelaskan bahwa ketika dilakukan perbandingan terhadap apa yang terjadi di nuclear family dan extended family, maka hal yang akan ditemukan adalah extended family lebih rentan terhadap permasalahan antara keluarga batih (ayah, ibu, dan anak) dan keluarga luas, seperti kakek, nenek, dan lain-lain yang berdampak pada PSE ayah.

Malelak \& Afiatin (2015) juga mengungkap bahwa ayah yang berusia remaja dengan bentuk keluarga extended family memicu timbulnya perasaan yang berkeinginan untuk tinggal secara mandiri (menjadi nuclear family) sebab orang tua seringkali merasa lebih berpengalaman, merasa lebih tahu banyak hal sehingga mencampuri berbagai urusan dalam keluarga tanpa memperhitungkan keberadaan ayah remaja tersebut. Disamping itu ayah remaja juga merasa bahwa posisi nya kerap kali rancu sebab harus menjadi ayah untuk anaknya, namun sekaligus menjadi anak dari orang tuanya yang berarti berusaha mengikuti otoritas orang tuanya tersebut. Kelemahan extended family yang berkaitan erat dengan timbulnya masalah perilaku pada anak dan stress yang dialami orang tua dapat dihubungkan dengan karakteristik PSE yang rendah yakni stress dan depresi yang dialami oleh orang tua dan masalah dalam perilaku anak (Sevigny \& Loutzenhiser, 2013).

Berdasarkan penjelasan di atas, maka dapat diketahui bahwa parenting tidak hanya berfokus pada ibu, akan tetapi keterlibatan ayah turut memberikan kontribusi besar terhadap perkembangan anak ke arah positif seperti membentuk kemandirian dan kepercayaan diri anak. Hal penting yang melandasi keterlibatan ayah adalah PSE yang dimilikinya, selain itu aspek PSE ini dapat dikaitkan dengan bentuk keluarga dimana ayah tersebut berada. Dengan demikian penelitian ini urgen untuk dilaksanakan sebab 
akan diungkap apakah ada perbedaan PSE ayah pada nuclear family dan extended family serta melihat gambaran PSE ayah berdasarkan kedua bentuk keluarga tersebut. Manfaat dari penelitian ini terbagi atas dua, yakni manfaat teoritis dan manfaat praktis. Secara teoritis, hasil penelitian ini akan memberikan informasi mengenai perbedaan antara PSE ayah pada nuclear family dan extended family, serta memberikan gambaran tentang PSE ayah pada nuclear family dan PSE ayah pada extended family. Disamping itu, manfaat praktis yang dapat diperoleh adalah hasil penelitian ini mampu memberikan informasi kepada masyarakat, khususnya orang tua dan lembaga yang bertanggung jawab agar mengembangkan kegiatan yang bersifat mengoptimalkan PSE pada ayah berdasarkan bentuk keluarga yang dimiliki, khususnya nuclear family dan extended family.

\section{METODE}

\section{Rancangan Penelitian}

Metode yang akan digunakan dalam penelitian ini adalah kuantitatif komparasi yaitu penelitian yang hendak melakukan perbandingan terhadap kelompok yang berbeda dan menggunakan data berupa angka untuk menemukan keteterangan yang ingin diketahui (Darmawan, 2016). Secara spesifik, penelitian ini akan membandingkan PSE ayah pada bentuk keluarga yang berbeda dengan cara menyelidiki gambaran (tingkat) PSE ayah pada masing-masing bentuk keluarga tersebut, yaitu nuclear family dan extended family.

\section{Subyek Penelitian}

Teknik sampling yang digunakan adalah teknik snowball sampling, yaitu ketika pada awalanya peneliti hanya mengetahui beberapa jumlah sampel lalu dari segelintir sampel tersebut menunjukkan kepada peneliti bahwa ada orang lain yang dapat dijadikan subjek penelitian, dan begitu seterusnya. Ukuran sampel yang akan digunakan berpedoman pada pendapat dari (Darmawan, 2016) bahwa sebaiknya ukuran sampel dalam suatu penelitian adalah antara 30 sampai dengan 500 elemen sehingga subjek dalam penelitian ini sebanyak 200 orang yang terdiri atas dua kelompok, 100 ayah pada nuclear family dan 100 ayah dari extended family dengan cara mencari individu yang sesuai dengan karakteristik subjek penelitian. Nuclear family adalah keluarga yang anggota keluarganya terdiri atas ayah, ibu, dan anak, sedangkan extended family yaitu keluarga yang beranggotakan keluarga batih (ayah, ibu, dan anak) beserta anggota keluarga luas, seperti kakek/ nenek, tante, dan lain-lain. Karakteristik ayah pada kedua kelompok tersebut adalah berusia 20 hingga 40 tahun dan tidak bercerai.

\section{Variabel dan Instrumen Penelitian}

Variabel yang digunakan dalam penelitian ini terdiri atas dua variabel yakni variabel dependent atau yang disebut sebagai variabel terikat (Y) yang berperan untuk mempengaruhi variabel independent atau variabel bebas (X). Parenting self-efficacy (PSE) ayah merupakan variabel dependent yaitu keyakinan yang dimiliki oleh ayah terhadap kompetensinya sebagai orang tua dan meyakini diri bahwa ia mampu untuk mempengaruhi perkembangan anak menjadi lebih positif. Variabel dependent tersebut diduga dipengaruhi oleh variabel independent yaitu bentuk keluarga yang dimiliki oleh ayah, dimana bentuk keluarga yang dimaksud adalah nuclear dan extended family. Ayah yang mempunyai bentuk keluarga nuclear yaitu anggota keluarga hanya terdiri atas ibu, anak, dan ayah itu sendiri sedangkan extended family adalah keluarga yang terdiri atas ayah itu sendiri, ibu, anak, dan anggota keluarga lainnya seperti kakek, nenek, dan sebagainya. 
Sesuai dengan tujuan penelitian yakni mengetahui PSE ayah pada extended family dan nuclear family, maka dibutuhkan data PSE ayah yang diketahui melalui penggunaan instrumen dalam bentuk skala. Skala yang digunakan adalah Father Self- Efficacy Scale (FSES) yang telah disusun oleh Sevigny (2013). Skala ini terdiri atas 22 item dan tersusun atas 9 dimensi yaitu, dimensi teaching, parenting in context, financial responsibility, safety and protection, discipline and control, nurturing, accessibility, instrumental care and routines, dan play.

Alat ukur ini menggunakan bahasa Inggris dengan nilai item indeks validitas sebesar $0.528-0.886$ dan indeks realibilitas (alpha) adalah 0.91, setelah itu, agar alat ukur ini dapat diaplikasikan kepada subjek maka dilakukan adaptasi dari bahasa inggris ke bahasa Indonesia dan dilakukan uji validitas dan realibilitas menggunakan software for windows SPSS ver. 23. Hasil uji validitas untuk alat ukur FSES versi bahasa Indonesia berisi 19 item, item indeks validitas sebesar $0.264-0.691$ dan realibilitasnya adalah 0.905 .

\section{Prosedur dan Analisa Data}

Secara garis besar, terdapat tiga prosedur utama dalam melaksanakn penelitian ini yaitu tahap persiapan, pelaksanaan, dan analisa data. Tahap persiapan dimulai dengan melakukan pendalaman materi, perancangan desain penelitian, dan adaptasi alat ukur yang diikuti dengan try out terhadap sampel yang homogen dengan subjek penelitian. Tahapan selanjutnya adalah pelaksanaan, yakni pengambilan data dengan cara membagikan skala FSES yang telah melalui tahapan try out kepada 60 subjek kemudian dilakukan pengambilan data kepada sebanyak 100 orang yang masing-masing terdiri atas 50 ayah dengan extended family dan 50 ayah dengan nuclear family.

Tahapan terakhir adalah menganalisa data yang telah diperoleh dengan menggunakan analisis parametrik (jumlah subjek $>30$ orang). Adapun perhitungan teknik analisa statistika yang digunakan berupa uji Mann Whitney, statistika deskriptif, dan uji Kruskal Wallis melalui software for windows ver. SPSS 23 sebagai program pengolahan data. Uji Mann Whitney merupakan alternative uji $\mathrm{t}$ dan uji $\mathrm{z}$ untuk variabel independen yang hanya berjumlah 2 sampel, serta keduanya tidak berhubungan satu dengan lainnya (Santoso, 2015). Winarsunu (2009) menjelaskan bahwa teknik uji t merupakan teknik statistik yang dipergunakan untuk menguji signifikansi perbedaan 2 buah mean yang berasal dari dua buah distribusi, dengan kata lain teknik ini digunakan untuk menganalisa apakah terjadi perbedaan signifikan atau tidak signifikan antara 2 sampel. Perbedaan yang signifikan yang dimaksud adalah perbedaan tersebut tidak saja terjadi pada sampel yang diteliti, namun juga terdapat pada populasi. Sebaliknya, tidak signifikan menandakan bahwa perbedaan tersebut kebetulan saja terjadi pada sampel dan tidak terdapat pada populasi ang biasanya diakibatkan oleh kesalahan dalam pengambilan sampel (sampling error). Independent t-test dalam penelitian ini digunakan untuk menganalisa tingkat PSE ayah pada extended family sebagai satu kelompok dan nuclear family sebagai kelompok lainnya.

Teknik analisa statistika selanjutnya adalah statistik deskriptif, yaitu penyusunan data kedalam daftar, grafik, atau bentuk lain yang sama sekali tidak menyangkut penarikan kesimpulan (Winarsunu, 2009). Aplikasi teknik statisk deskriptif dalam penelitian ini digunakan untuk melihat gambaran umum mengenai persebaran demografis pada subjek penelitian. Secara mendetail, aspek demografis seluruh subjek, baik pada nuclear family 
maupun extended family diantaranya adalah usia subjek, pekerjaan, jumlah penghasilan per-bulan, pendidikan terakhir, jumlah anak, dan jenis kelamin anak, serta data demografis istri. Setelah melakukan statistik deskriptif, teknik analisa selanjutnya adalah uji Kruskal Wallis yakni analisis statistik untuk menguji lebih dari 2 sampel yang tidak berhubungan sebagai alternatif uji ANOVA jika asumsi pada uji ANOVA tersebut tidak terpenuhi (Santoso, 2015). Penelitian ini menggunakan uji Kruskal Wallis sebagai analisis tambahan yang bertujuan menghubungkan data demografis subjek pada masingmasing kelompok yaitu nuclear family maupun extended family yang kemungkinan memiliki hubungan dengan tingkat PSE.

\section{HASIL}

Penelitian telah dilaksanakan kepada dua kelompok subjek yakni ayah pada nuclear family dan extended family. Berikut ini akan diuraikan hasil penelitian dan analisis data untuk mengidentifikasi perbandingan PSE ayah pada dua bentuk keluarga tersebut, yakni nuclear dan extended family.

Tabel 1. Deskripsi Subjek Penelitian

\begin{tabular}{clcc}
\hline & Kategori & $\begin{array}{c}\text { Nuclear } \\
\text { Family } \\
\text { f }\end{array}$ & $\begin{array}{c}\text { Extended } \\
\text { Family } \\
\text { F }\end{array}$ \\
\hline Usia & 20-25 tahun & 11 & 10 \\
& 26-30 tahun & 19 & 25 \\
& $31-35$ tahun & 23 & 17 \\
& 36-40 tahun & 47 & 48 \\
\hline Pendidikan & SD & 0 & 0 \\
Terakhir & SMP & 4 & 7 \\
& SMA Sederajat & 33 & 34 \\
& D1-D2-D3 & 10 & 9 \\
& S1-S2-S3 & 53 & 50 \\
\hline Jenis & PNS & 28 & 18 \\
Pekerjaan & Karyawan Swasta & 43 & 50 \\
& Karyawan BUMN & 7 & 1 \\
& Wiraswasta & 22 & 31 \\
\hline \multirow{2}{*}{ Jumlah } & Reng.1.000.000 & 1 & 5 \\
Per-bulan & Rp.1.000.000-Rp.5.000.000 & 79 & 73 \\
& Rp.5.100.000-Rp.10.000.000 & 15 & 22 \\
& $>$ Rp.10.000.000 & 5 & 0 \\
\hline
\end{tabular}

Tabel 1 menunjukkan bahwa subjek pada penelitian ini berusia minimum 20 tahun dan maksimum 40 tahun. Adapun rentang usia dengan jumlah frekuensi subjek tertinggi berada pada usia 36-40 tahun, yakni sebanyak 47 untuk nuclear family dan 48 di extended family. Sebaliknya, jumlah frekuensi terendah terletak pada rentangan usia 2025 tahun yaitu 11 orang dalam nuclear family dan 10 orang pada extended family. Selain itu, data demografis berdasarkan pendidikan terakhir diperoleh jumlah frekuensi subjek tertinggi adalah Strata (S1-S2-S3) sebanyak 53 pada nuclear dan 50 pada extended family. Bagian berikutnya menunjukkan jenis pekerjaan dengan jumlah frekuensi tertinggi pada kedua bentuk keluarga adalah karyawan swasta sebanyak 43 orang untuk nuclear family dan 50 orang untuk exetended family.Berikutnya adalah jumlah penghasilan per-bulan dengan jumlah frekuensi tertinggi berada pada rentangan 
penghasilan Rp.1.000.000 - Rp.5.000.000.000 sebanyak 79 orang untuk nuclear family dan 73 orang pada extended family. Selain itu, dapat diidentifikasi bahwa tidak ada subjek dalam nuclear family yang memiliki penghasilan kurang dari Rp.1.000.000 sedangkan pada pada extended family, tidak ada subjek yang memiliki penghasilan di atas Rp.10.000.000.

Tabel 2. Deskriptif Uji Mann-Whitney

\begin{tabular}{|c|c|c|c|}
\hline Bentuk Keluarga & $\mathbf{N}$ & $\mathbf{Z}$ & $\mathbf{P}$ \\
\hline Nuclear Family & 100 & -1.273 & 0.216 \\
\hline Extended Family & 100 & & \\
\hline
\end{tabular}

Tabel 2 hasil pengujian tersebut menunjukkan nilai $\mathrm{p}=0.216$ ( $\mathrm{p}>0.05)$, serta Zhitung= 1.273 dengan $\alpha=5 \%$ dan Ztabel $=-1.96$ (Zhitung $>$ Ztabel) yang menandakan bahwa tidak terdapat perbedaan skor PSE yang signifikan antara ayah pada nuclear family dan ayah pada extended family. Sesuai dengan hal ini, maka dapat dikatakan bahwa hasil penelitian menunjukkan tidak ada perbedaan tingkat PSE ayah pada nuclear dan extended family.

\section{DISKUSI}

Hasil penelitian ini membuktikan bahwa terjadi penolakan hipotesa yang berarti tidak terdapat perbedaan signifikan PSE ayah pada nuclear dan extended family, dengan demikian perbedaan lingkungan sosial yakni bentuk keluarga nuclear dan extended tidak mempengaruhi perbedaan tingkat PSE ayah. Apabila diidentifikasi hal-hal yang berpotensi menjadi penyebab tidak adanya perbedaan PSE ayah di kedua bentuk keluarga tersebut dapat disebabkan oleh faktor budaya, seperti halnya yang disampaikan oleh Harmaini, et al. (2014) bahwa fungsi dan peran orang tua dalam keluarga tidak bisa dilepaskan dari pengaruh budaya orang tua tersebut. Apa yang diajarkan oleh budayanya tentang bagaimana dalam berkeluarga akan diturunkan ke anak secara turun temurun. Sebagaimana yang telah diketahui bahwa masyarakat Indonesia pada umumnya baik itu nuclear family maupun extended family masih ada yang mempersepsi bahwa ayah merupakan figur yang hanya bertanggung jawab pada aspek finansial sedangkan terlibat dalam pengasuhan anak merupakan hal yang masih tabu untuk dilakukan. Disamping itu, meskipun jumlah dukungan sosial yang dimiliki oleh ayah dalam nuclear family diindikasikan cukup minim sedangkan ayah pada extended family tampak memiliki dukungan sosial yang lebih banyak, namun hal ini tidak menghasilkan perbedaan PSE ayah sebab yang dibutuhkan oleh mereka adalah kualitas dari dukungan sosial tersebut khsusnya dukungan dari pasangan. Dukungan yang dimaksud disini dapat diindikasikan dalam bentuk pemberian kesempatan dan bantuan kepada ayah agar ia lebih terlibat dalam parenting. Dengan demikian dukungan sosial yang berkualitas dapat ditentukan dari kualitas hubungan dengan pasangan. Hal ini didukung oleh Kwok, et al. (2013) yang membuktikan bahwa kepuasan pernikahan berpengaruh secara signifikan terhadap PSE ayah yang disebabkan karena kepuasan pernikahan mampu membentuk atmosfer yang positif dalam keluarga, selain itu kepuasan pernikahan juga dapat menjembatani PSE ayah dan keterlibatan ayah melalui dorongan dari ibu (pasangan) agar ayah semakin terlibat dalam pengasuhan anak.

Selain itu, faktor lain yang kemungkinan berperan penting terhadap PSE ayah pada nuclear dan extended family sehingga tidak menimbulkan perbedaan PSE diantara keduanya adalah sumber dukungan sosial. Hal yang perlu disadari adalah dukungan sosial pada nuclear family kemungkinan tidak hanya didapatkan dari pasangan dan 
begitupun dengan ayah pada extended family yang tidak hanya mendapatkan dukungan dari pasangan dan keluarga luas, akan tetapi dukungan sosial ini dapat di peroleh dari berbagai sumber. Sumber dukungan sosial tersebut diantaranya berasal dari teman atau bahkan dari tenaga professional. Sebagaimana yang dikemukakan oleh Salonen (2010) bahwa saran dari perawat yang professional (professional nursing) merupakan faktor yang berpengaruh secara signifikan terhadap tingkat PSE ayah baru. Disamping itu, untuk mendapatkan peningkatan PSE ayah yang baru memiliki bayi maka berbagai faktor harus saling berkaitan diantaranya adalah keberfungsian keluarga, kesehatan keluarga, bantuan dan dukungan dari pihak professional, keberadaan ayah di rumah sakit ketika ibu (pasangan) melahirkan, dan lain sebagainya.

Selain kualitas dukungan sosial dan sumber perolehan dukungan sosial, faktor vicarious experience juga turut menjadi perihal yang diduga sebagai penyebab terjadinya penolakan hipotesa. Coleman \& Karraker (1997) menyatakan bahwa salah satu faktor yang mempengaruhi PSE adalah vicarious experience, yakni pengalaman mengamati orang lain akan membentuk suatu keyakinan pada diri terhadap kompetensi yang dimiliki. Berdasarkan asumsi awal faktor ini akan lebih dominan pada extended family sebab ayah akan belajar mengenai parenting melalui pengamatan yang ia lakukan terhadap keluarga luas khususnya generasi yang lebih tua sehingga berpengaruh terhadap PSE yang ia miliki. Akan tetapi vicarious experience ini pada dasarnya dapat didefinisikan lebih luas yakni sebagai pengamatan ayah mengenai parenting yang diterapkan orang tuanya khususnya ayah kepada drinya dahulu. Wood \& Lambin (2013) mengemukakan bahwa pengalaman ayah dengan orang tuanya mampu mempengaruhi peranannya dalam parenting. Ketika ayah dibesarkan oleh orang tua (ayah) yang kurang terlibat dalam pengasuhannya, maka ada kemungkinan ia akan melakukan hal yang serupa ketika menjalankan perannya sebagai ayah di kemudian hari. Hal ini tentunya menunjukkan bahwa pengalaman parenting dari orang tuanya (ayah) terdahulu mampu berkontribusi terhadap PSE yang ia miliki, dimana hal ini dapat terjadi pada ayah di nuclear maupun extended family.

Disamping menyelidiki apakah ada perbedaan tingkat PSE ayah pada nuclear dan extended family, hal lain yang telah diidentifikasi dalam penelitian ini adalah PSE ayah berdasarkan data demografis pada masing-masing bentuk keluarga. Secara keseluruhan, usia subjek dalam penelitian ini adalah 20-40 tahun yang didasari oleh suatu alasan bahwa padarentangan usia tersebut dikategorikan sebagai tahap fase dewasa awal, dimana tugas perkembangan yang dimiliki adalah menjalin relasi dengan lawan jenis yakni pernikahan dan menjadi orang tua (Santrock, 2012). Berkaitan dengan hal tersebut, hasil penelitian ini menunjukkan terjadi perbedaan tingkat PSE ayah yang signifikan berdasarkan usia ayah di extended family. Ayah yang berusia 20-25 tahun tergolong sebagai ayah dengan tingkat PSE tertinggi dibandingkan rentangan usia lainnya. Apabila diidentifikasi, kemungkinan terjadinya hal ini dapat dikaitkan dengan perkembangan teknologi yang semakin pesat. Didukung dengan yang dikemukakan oleh Fletcher \& StGeorge (2012) bahwa ayah yang tergabung dalam komunitas virtual yakni melalui percakapan (chat) online diantara para ayah akan membantu mereka untuk saling bertukar informasi mengenai tantangan-tantangan yang mereka hadapi dalam mengasuh anak dan hal-hal yang dilakukan untuk mengatasinya, serta saling mendukung sehingga komunitas virtual ini akan membantu para ayah, khususnya seseorang yang baru menjadi 
ayah untuk belajar dari pengalaman satu sama lainnya. Hal ini membuktikan bahwa mereka dapat memperoleh dukungan sosial dari berbagai sumber yang didukung dengan komunikasi yang semakin mudah akibat kemajuan teknologi.

Data demografis lainnya yang menunjukkan hasil signifikan adalah PSE ayah berdasarkan pekerjaan ayah pada extended family, yakni ayah yang bekerja sebagai karyawan BUMN menduduki nilai mean tertinggi dibandingkan ayah dengan jenis pekerjaan lainnya. Disamping itu, hasil lainnya menunjukkan bahwa terjadi perbedaan signifikan pada penghasilan per-bulan dari ayah nuclear family. Sasaki (2012) mengemukakan bahwa persepsi mengenai nilai dan perannya sebagai ayah terhadap anak yang dapat meningkatkan keterlibatannya dalam pengasuhan anak didorong oleh kepuasan kerja yang dimilikinya. Dengan demikian hasil signifikan tersebut dapat disebabkan karena kepuasan ayah terhadap pekerjaannya sehingga berpengaruh terhadap $P S E$ ayah.

Penelitian ini telah dilaksanakan sebaik mungkin sebagaimana kemampuan dari peneliti,akan tetapi keterbatasan yang dihadapi adalah sulitnya memberikan instruksi secara langsung dan mendampingi subjek ketika mengisi skala (alat ukur). Hal ini disebabkan karena kesibukan dari subjek, sehingga mereka meminta waktu untuk dapat mengisi skala tersebut. Disamping itu, skala yang digunakan adalah alat ukur yang diadaptasi dari penelitian yang ditujukan kepada ayah yang baru memiliki bayi sebagai subjek penelitiannya. Disisi lain, subjek dalam penelitian ini tidak hanya ditujukan kepada ayah yang baru.

\section{SIMPULAN DAN IMPLIKASI}

Berdasarkan hasil penelitian, maka dapat disimpulkan bahwa hipotesa ditolak yang berarti tidak ada perbedaan secara signifikan terhadap PSE ayah pada nuclear dan extended family. Penelitian ini menandakan PSE ayah tidak dipengaruhi oleh bentuk keluarga yang dimiliki. Hal ini disebabkan karena PSE ayah dapat dipengaruhi oleh kualitas dukungan sosial, sumber dukungan sosial, pengamatan terhadap parenting dari orang tuanya (ayah) terdahulu, dan bahkan faktor budaya yakni pandangan masyarakat terhadap peranan ayah juga turut menjadi faktor yang berpotensi menyebabkan penolakan hipotesa.

Implikasi dari hasil penelitian ini terhadap masyarakat, khususnya ayah yang memiliki $P S E$ rendah agar hendaknya melakukan aktivitas yang dapat meningkatkan PSE yang dimiliki seperti mencari informasi terkait peranan ayah terhadap perkembangan psikologis anak, semakin terlibat dalam pengasuhan anak, serta semakin meningkatkan kualitas hubungan bersama pasangan dan anggota keluarga lainnya. Disamping itu, hendaknya ibu (pasangan) dan lingkungan sekitar memberikan dukungan dan kesempatan kepada ayah agar ia mampu memiliki PSE yang tinggi dan semakin terlibat dalam pengasuhan sehingga anak dapat mencapai perkembangan psikologis yang optimal. Implikasi selanjutnya ditujukan kepada peneliti berikutnya agar mampu memberikan petunjuk pengerjaan skala secara langsung kepada subjek penelitian dan 
mendampingi mereka ketika mengisi skala (alat ukur). Disamping itu, apabila hendak melakukan penelitian dengan subjek yang serupa sebaiknya gunakan skala PSE ayah yang bersifat general. Sebaiknya peneliti berikutnya juga dapat mengidentifikasi jam kerja ayah, jumlah waktu dan bentuk aktivitas yang dilakukan setiap harinya oleh ayah bersama anaknya, serta bagi kelompok extended family sebaiknya diidentifikasi frekuensi dan intensitas ayah berkomunikasi dengan keluarga luas, seperti orang tua.

\section{REFERENSI}

Adimora, D. E., Nwokenna, E. N., Omeje, J. C., \& Umeano, E. C. (2015). Parenting styles and attention deficit hyperactivity disorder as correlates of academic adjustment of in-school adolescents in Enugu state, Nigeria. Procedia-Social and Behavioral Sciences, 205, 702-708.

Andayani, B. (2000). Profil keluarga anak-anak bermasalah. Jurnal Psikologi, 27(1), 1022.

Bansal, S. B., Dixit, S., Shivram, G., Pandey, D., \& Saroshe, S. (2014). A study to compare various aspects of members of joint and nuclear family. Journal of Evolution of Medical and Dental Sciences, 1(3), 641-648.

Coleman, P. K., \& Karraker, K. H. (1997). Self-efficacy and parenting quality: Findings and future applications. Developmental Review, 18(1), 47-85.

Coleman, P. K., \& Karraker, K. H. (2002). Parenting self-efficacy among mothers of school-age children: Conceptualization, measurement, and correlates. Family Relations, 49(1), 13-24.

Dagun, S. M. (2013). Psikologi keluarga (peranan ayah dalam keluarga). Jakarta: Rineka Cipta.

Darmawan, D. (2016). Metode penelitian kuantitatf. Bandung: Rosda.

Edlund, L., \& Rahman, A. (2005). Household structure and child outcomes: nuclear vs. extended families evidence from bangladesh. UCL and Columbia University: Mimeo.

Fletcher, R., \& StGeorge, J. (2011). Heading into fatherhood-nervously: Support for fathering from online dads. Qualitative Health Research, 21(8), 1101-1114.

Fogarty, K., \& Evans, G. D. (2009). The hidden benefits of being an involved father. Department of family, youth and community sciences, Florida cooperative extension service, Institute of food and agricultural sciences, University of Florida.

Freistadt, J., \& Strohschein, L. (2012). Family structure differences in family functioning interactive effects of social capital and family structure. Journal of Family Issues, 34(7), 952-974.

Gao, L. L., Sun, K., \& Chan, S. W. C. (2014). Social support and parenting self-efficacy among Chinese women in the perinatal period. Midwifery, 30(5), 532-538.

Garcia, A. S., \& Alampay, L. P. (2012). Parental efficacy, experience of stressful life events, and child externalizing behavior as predictors of Filipino mothers' and fathers' parental hostility and aggression. Philippine Journal of Psychology, 45(1), 1. 
Harmaini, H., Shofiah, V., \& Yulianti, A. (2015). Peran ayah dalam mendidik anak. Jurnal Psikologi, 10(2), 80-85.

Harty, M. (2009). The validation of a task-specific measure of parenting self-efficacy for use with mothers of young children. Doctoral dissertation, University of Pretoria.

Hashmi, S. I., Nawi, N. H. M., Seok, C. B., \& Halik, M. H. (2014). “Am i a super mom”, malaysian working mothers believes about their parenting self-efficacy. In proceedings of the conference held in Universiti Malaysia Sabah.

Herawaty, Y., \& Wulan, R. (2013). Hubungan antara keberfungsian keluarga dan daya juang dengan belajar berdasar regulasi diri pada remaja. Jurnal Psikologi, 9(2), 138-147.

Hsieh, R. L., Huang, H. Y., Lin, M. I., Wu, C. W., \& Lee, W. C. (2008). Quality of life, health satisfaction and family impact on caregivers of children with developmental delays. Child: Care, Health and Development, 35(2), 243-249.

Junttila, N., Aromaa, M., Rautava, P., Piha, J., \& Räihä, H. (2015). Measuring Multidimensional Parental Self-Efficacy of Mothers and Fathers of Children Ages 1.5 and 3 Years. Family Relations, 64(5), 665-680.

Kazdin, A. (2014) Encyclopedia of psychology. Retrieved from http://apa.org/pubs/books/4600100.aspx.

Kwok, S. Y., Ling, C. C., Leung, C. L., \& Li, J. C. (2013). Fathering self-efficacy, marital satisfaction and father involvement in Hong Kong. Journal of Child and Family Studies, 22(8), 1051-1060

Lestari, S. (2012). Psikologi keluarga: penanaman nilai dan penanganan konflik dalam keluarga. Jakarta: Kencana Prenada Media Group.

Malelak, V. Y., \& Afiatin, T. (2015). Makna peran ayah pada ayah remaja. Jurnal Psikologi "MANDIRI", 1(2).

Montigny, D. F., \& Lacharité, C. (2005). Perceived parental efficacy: Concept analysis. Journal of Advanced Nursing, 49, 387-396.

Ormrod, J. E. (2008). Psikologi pendidikan. $\left(6^{\text {th }}\right.$ ed). Jakarta: Penerbit Erlangga.

Pajares, F., \& Urdan, T. C. (2005). Self-efficacy beliefs of adolescents. New York: IAP.

Poland, M., Paterson, J., Carter, S., Gao, W., Perese, L., \& Stillman, S. (2007). Pacific islands families study: factors associated with living in extended families one year on from the birth of a child. Kōtuitui: New Zealand Journal of Social Sciences Online, 2(1), 17-28.

Republik Indonesia. Undang-Undang Nomor 52 Tahun 2009 tentang Perkembangan Kependudukan dan Keluarga Berencana. Jakarta: Sekretaris Negara Republik Indonesia.

Salonen, A. (2010). Parenting satisfaction and parenting self-efficacy during the postpartum period: evaluation of an internet-based intervention. Academic dissertation, Faculty of Medicine, University of Tampere.

Santoso, S. (2015). Spss 20: Pengolahan data statistik di era informasi. Jakarta: Kompas Gramedia. 
Santrock, J. W. (2012). Life span development: Perkembangan masa hidup (13 ${ }^{\text {th }}$ ed). Jakarta: Penerbit Erlangga.

Sasaki, T. (2012). Fathers' perception toward work and child care involvement: an application of identity theory and gender role ideology. Proceedings, 17, 111-120.

Sevigny, P. R. (2013). Understanding parental self-efficacy in fathers. Doctoral dissertation, Faculty of Graduate Studies and Research, University of Regina.

Sevigny, P. R., \& Loutzenhiser, L. (2009). Predictors of parenting self-efficacy in mothers and fathers of toddlers. Child: Care, Health and Development, 36(2), 179189.

Sevigny, P. R., Loutzenhiser, L., \& McAuslan, P. (2016). Development and validation of the fathering self-efficacy scale. Psychology of Men \& Masculinity, 17(1), 92.

Trahan, M. H. (2017). Paternal self-effiacy and father involvement: A bi-directional relationship. In proceedings of the society for social work and research $21^{\text {st }}$ annual conference- ensure healthy development for all youth.

Volker, J., \& Gibson, C. (2014). Paternal involvement: A review of the factors influencing father involvement and outcomes. TCNJ J Stud Scholar, 15, 1-8.

Winarsunu, T. (2009). Statistik dalam Penelitian Psikologi dan Pendidikan. Malang: UMM Press.

Wood, L., \& Lambin, E. (2013). How fathers and father figures can shape child health and wellbeing. The University of Western Australia.

Yorburg, B. (2002). Family realities: A global view. New Jersey: Prentice Hall. 